\title{
Validation of minimally invasive measurement of myocardial perfusion using electron beam computed tomography and application in human volunteers
}

\author{
M R Bell, L O Lerman, J A Rumberger
}

\begin{abstract}
Objectives-To measure myocardial perfusion using an estimate of intramyocardial vascular volume obtained by electron beam computed tomography (EBCT) in an animal model; to assess the feasibility and validity of measuring regional myocardial perfusion in human volunteers using the techniques developed and validated in the animal studies.

Methods-Measurements of myocardial perfusion with EBCT employing intravenous contrast injections were compared with radioactive microsphere measurements (flow 57 to $346 \mathrm{ml} / 100 \mathrm{~g} / \mathrm{min}$ ) in seven closed chest dogs. Fourteen human volunteers then underwent EBCT scans using intravenous contrast injections.

Results-Mean (SEM) global intramyocardial vascular volume by EBCT was 7.6 $(1.1) \%$. The correlation between global EBCT (y) and microsphere (x) perfusion was $\mathrm{y}=0.59 \mathrm{x}+15.56(r=0.86)$ before, and $\mathrm{y}=0.72 \mathrm{x}+6.06(r=0.88)$ after correcting for intramyocardial vascular volume. Regional perfusion correlation was $y=0.75 x+23.84(r=0.82)$. Corresponding improvements in agreement between the two techniques were also seen using Bland-Altman plots. In the human subjects, mean resting global myocardial flow was 98 (6) $\mathrm{ml} / 100 \mathrm{~g} / \mathrm{min}$, with homogeneous flow across all regions. In 10 of these subjects, perfusion was studied during coronary vasodilatation using intravenous adenosine. Global flow increased from 93 (5) $\mathrm{ml} / 100 \mathrm{~g} / \mathrm{min}$ at rest to $250(19) \mathrm{ml} / 100$ g/min during adenosine $(p<0.001)$, with an average perfusion reserve ratio of 2.8 $(0.2)$. Similar changes in regional perfusion were observed and were uniform throughout all regions, with a mean regional perfusion reserve ratio of 2.8 (0.3).
\end{abstract}

Conclusions-Accounting for intramyocardial vascular volume improves the accuracy of EBCT measurements of myocardial perfusion when using intravenous contrast injections. The feasibility of providing accurate measurements of global and regional myocardial perfusion and perfusion reserve in people using this minimally invasive technique has also been demonstrated.

(Heart 1999;81:628-635)
Keywords: electron beam computed tomography; cardiac imaging; myocardial blood flow; indicator dilution

Among patients with coronary artery disease undergoing selective coronary angiography, the severity of individual coronary artery stenoses is generally defined by simple geometric measurements of the visualised lumen, but has well documented limitations. ${ }^{1-6}$ Measurement of the physiological significance of such stenoses, such as the measurement of absolute myocardial perfusion (that is, as $\mathrm{ml} / \mathrm{g} / \mathrm{min}$ ), would greatly complement coronary angiography.

Intracoronary Doppler measurements of coronary flow velocity and flow reserve have increased the clinical awareness of the value of physiological measurements of coronary artery stenoses $^{7-11}$ but requires catheterisation, has some important technical limitations, and is unable to provide absolute measurements of flow. Coronary flow reserve can be influenced by small changes in resting values such as occur with alterations in heart rate and blood pressure. Absolute determination of the maximum flow rate will potentially overcome such limitations in the interpretation of flow reserve ratios. However, methods to quantify myocardial perfusion in absolute terms are quite limited in people compared with sophisticated techniques available in animals. ${ }^{12}$

Positron emission tomography ${ }^{13-15}$ and electron beam computed tomography (EBCT) ${ }^{16-19}$ show promise for the absolute quantification of global and regional myocardial perfusion in human subjects. EBCT measurements from our laboratory ${ }^{17}$ and others, ${ }^{16}{ }^{19}$ employing venous injections of iodinated contrast, have underestimated absolute myocardial perfusion (that is, flow per unit volume), particularly at higher flow rates. Several reasons for this observation have been postulated and include the use of intravenous rather than intra-aortic injections of contrast and failure to correct for intramyocardial vascular volume (that is, the volume within the myocardium that is entirely vascular), which is known to increase as myocardial blood flow increases. ${ }^{20}$ Wang et al, using intra-aortic root injections of contrast, ${ }^{18}$ showed good correlation between measurements of myocardial flow by $x$ ray computed tomography (CT) and radioactive microspheres in dogs when accounting for intramyocardial vascular volume. However, intra-aortic 
or intracoronary injections of contrast have limited practical value in routine clinical practice.

The purposes of the present study were, first, in an animal model using intravenous injections of iodinated contrast to estimate intramyocardial vascular volume by EBCT, characterise how this changes during vasodilatation, and assess whether correction for this variable improves the validity of EBCT measurements of myocardial perfusion. Additional studies were then performed to assess the feasibility and validity of measuring regional myocardial perfusion in human subjects using the techniques developed and validated in these animal studies.

\section{Methods}

ANIMAL STUDIES

Animal preparation

Approval was obtained from the Mayo Clinic institutional animal care and utilisation committee to perform the following validation study, and each experiment was conducted in accordance with institutional guidelines. Seven closed chest dogs (mean weight $22 \mathrm{~kg}$; range 18 to $24 \mathrm{~kg}$ ) were anaesthetised with $1 \mathrm{ml} / 10 \mathrm{~kg}$ of Innovar-Vet (droperidol-fentanyl mixture) and $13 \mathrm{mg} / \mathrm{kg}$ of sodium pentobarbitone intravenously. Each dog was intubated and ventilated with room air using a Harvard respirator. Supplemental anaesthesia was provided with sodium pentobarbitone and/or Innovar-Vet.

The left and right femoral arteries and veins and the right internal jugular vein were surgically exposed. A $5 \mathrm{~F}$ angiographic pigtail catheter was inserted through the right femoral vein and positioned under fluoroscopy in the inferior vena cava at the level of the diaphragm. A $6 \mathrm{~F}$ catheter was inserted through the right jugular vein and into the right atrium and advanced across the atrial septum into the left atrium for injection of radioactive microspheres. An 8 F Rodrigues catheter was placed in the left femoral artery and connected to a withdrawal syringe for arterial blood sampling of microspheres. The left femoral vein was used as access for fluid replacement and drug administration.

Experimental protocol

EBCT scan procedure-The Imatron C-100 EBCT scanner (Imatron Inc, South San Francisco, California, USA) has been described in detail previously. ${ }^{21}$ The dogs were positioned on their left side and the table was skewed about $20^{\circ}$ to facilitate acquisition of images from the cardiac short axis. Electrocardiographic triggering of the scanner was used.

Scans were performed during injection of 42 $\mathrm{ml}$ of dilute iohexol-370 (iohexol to normal saline ratio of $1: 3$; approximately $0.5 \mathrm{ml}$ iohexol $/ \mathrm{kg}$ ) into the inferior vena cava over 2.5 seconds using an angiographic power injector with the ventilator turned off. The injection was initiated three seconds before scanning to enable baseline recording of myocardial and left ventricular cavity CT numbers (Hounsfield units). Twenty serial images were acquired through each of four contiguous tomographic levels ( $1 \mathrm{~cm}$ spacing), with each image acquired at end diastole of every or every other cardiac cycle, depending on the heart rate. ${ }^{17}$ Scans were performed at rest and during coronary vasodilatation by intravenous adenosine ( 0.5 to $1.5 \mathrm{mg} / \mathrm{kg} / \mathrm{min}$ ).

Radiolabelled microsphere administrationImmediately before each scan, arterial blood was continuously withdrawn at $7.5 \mathrm{ml} / \mathrm{min}$ from the femoral artery into a heparinised syringe connected to a withdrawal pump. Approximately $5 \times 10^{6}$ uniquely labelled radioactive microspheres $\left(\mathrm{Sn}^{113}, \mathrm{Co}^{57}, \mathrm{Sr}^{85}\right.$, or $\left.\mathrm{Sc}^{46}\right)$ were injected into the left atrium during each scan and peripheral blood withdrawn for two minutes. At the conclusion of the experiment, the dogs were killed and the heart removed and fixed in formalin for at least four days.

\section{Data analysis}

Microsphere measurements-The left ventricle was dissected free from the excised heart, and the atrioventricular valves removed and divided into consecutive $8 \mathrm{~mm}$ thick slices parallel to the short axis. Four of these slices were then matched to their corresponding EBCT images using internal landmarks for reference. Each slice was cut into radially oriented sectors, divided into segments weighing $0.5 \mathrm{~g}$ to $1.0 \mathrm{~g}$, and placed into labelled glass tubes. Reference blood samples were divided into $3 \mathrm{ml}$ aliquots in glass tubes. All tubes were then placed in a gamma well counter and counted for radioactivity using a sodium iodide detector. These data were analysed by the matrix inversion technique with application of an appropriate spillover correction for each tracer.

Myocardial blood flow was calculated using the following algorithm:

Flow $(\mathrm{ml} / 100 \mathrm{~g} / \mathrm{min})=\left(\mathrm{C}_{\mathrm{m}} \times 7.5 \times\right.$ $100) /\left(\mathrm{Wt}_{\mathrm{m}} \times \mathrm{C}_{\mathrm{r}}\right)$

where $\mathrm{C}_{\mathrm{m}}=$ radioactivity counts in myocardium, $7.5=$ reference blood flow $(\mathrm{ml} / \mathrm{min})$, $\mathrm{Wt}_{\mathrm{m}}=$ weight of each segment of myocardium in grams, and $\mathrm{C}_{\mathrm{r}}=$ counts in reference blood samples. Global and regional flows were determined by averaging the flow per unit weight for each specific slice and region.

Indicator dilution curves from EBCT-Contrast density versus time curves were recorded separately from adjacent tomographic slices at the mid-left ventricular level and were obtained through the entire tomographic slice (global flow) of the left ventricle and four equal regions (anterior, septal, lateral, and posterior). The indicator dilution curve from the left ventricular cavity was used as the arterial input function. ${ }^{16} 1922$ To avoid partial volume effects, tracing of the myocardium was performed a few pixels inside the endo and epicardial borders.

Estimation of intramyocardial vascular volumeThe intramyocardial vascular volume was defined as that proportion of the total tissue volume composed of the volume of vascular space per unit volume of myocardium $(\beta) .^{18}{ }^{23}$

It is assumed that muscle and vasculature are separate volumes and that, in vivo, the CT 


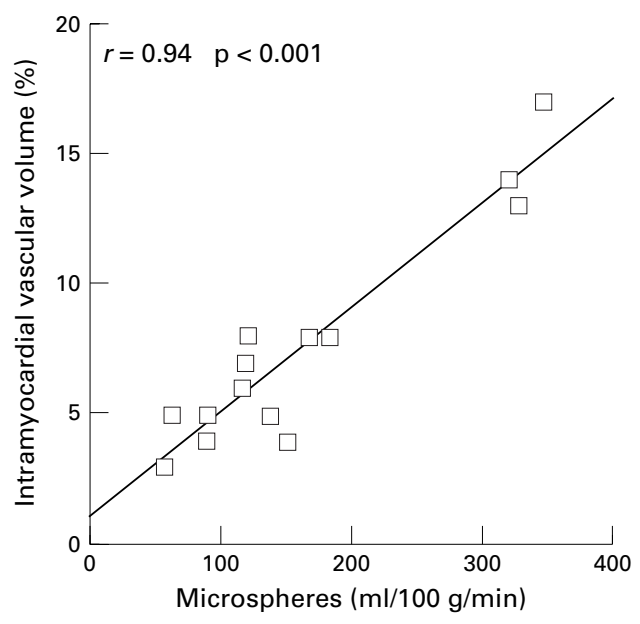

Figure 1 The change in intramyocardial vascular volume as a percentage of total myocardial tissue volume measured by electron beam computed tomography, shown as a function of myocardial perfusion obtained with radiolabelled microspheres.

"densities" of both are virtually identical. During the first pass of iodinated contrast, which a priori is assumed to remain almost entirely intravascular, ${ }^{24}{ }^{25}$ the concentration of iodine in the myocardium relative to that in a purely vascular space (for example, the left ventricular
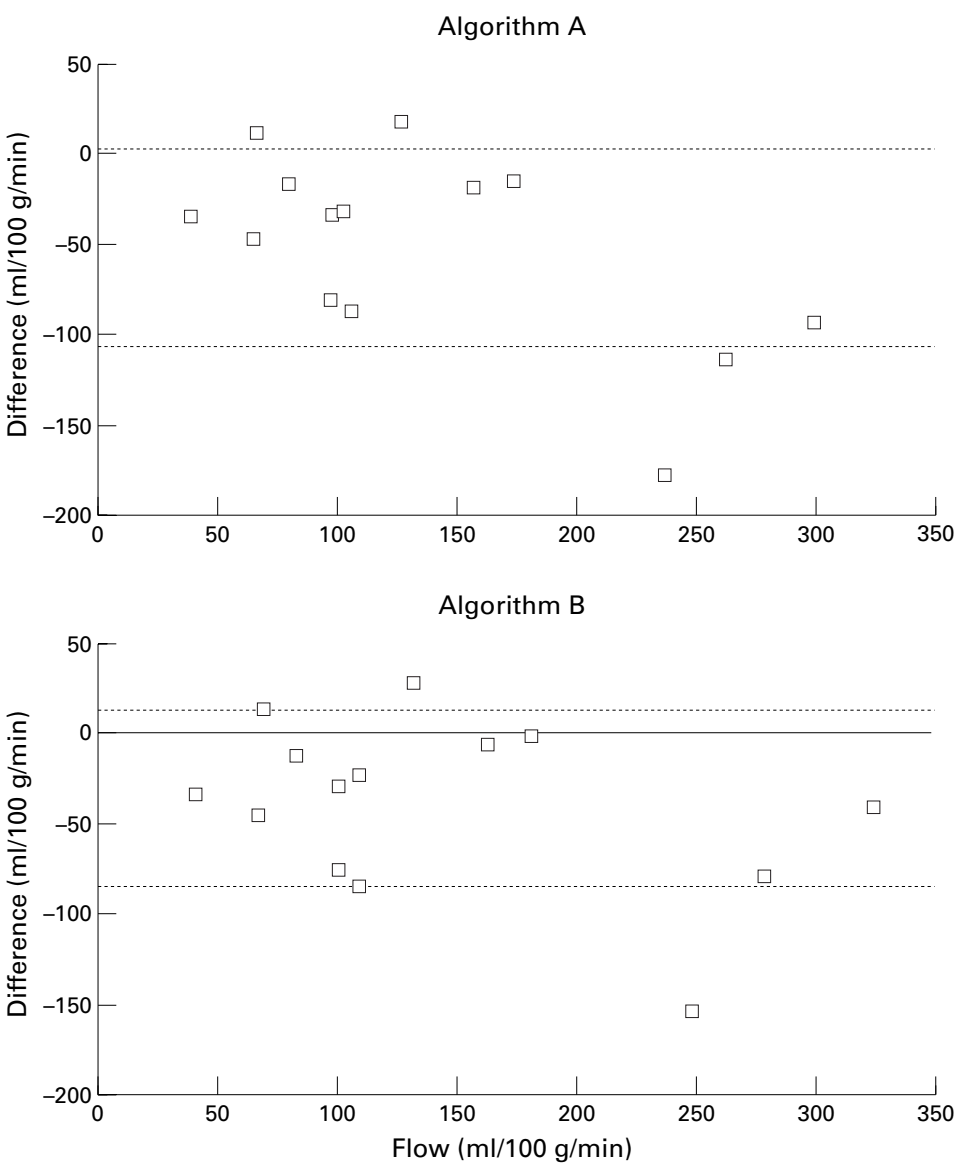

Figure 2 Bland and Altman plots showing comparison of EBCT global (tomographic) myocardial perfusion obtained in the canine experiments with radiolabelled microspheres. The abscissa is the mean of the EBCT and microsphere values and the ordinate is the difference between the two (EBCT minus microsphere). The dashed lines represent 1 standard deviation from the mean of the differences. (A) EBCT measurements have been obtained without correction for intramyocardial vascular volume (algorithm $A$ ); (B) after correcting for intramyocardial vascular volume (algorithm B). cavity) represents a "dilution" effect of the avascular component. The proportion of myocardial tissue that is purely avascular can be considered to "volume average" the myocardial tissue that is purely vascular.

To estimate $\beta$, the mean concentration of iodine (represented by the mean CT number) in the myocardium and left ventricular cavity were determined. An index of the mean concentration of contrast in a region of interest was defined as the mean of the CT densities above baseline during the first pass. This was calculated by defining the area under the gamma variate fit of the contrast-dilution curve and the time for the first pass. Assuming symmetry of the curve about the first moment $\left(\int \mathrm{tc}(\mathrm{t}) \mathrm{dt}\right)$, the first pass time can be estimated as twice the mean transit time; $\beta$ was then calculated from the ratio of the mean CT numbers within the region of interest $\left(\mathrm{CT}_{\mathrm{m}}\right)$ and the purely vascular left ventricular cavity $\left(\mathrm{CT}_{\mathrm{LV}}\right)$ and expressed as a percentage of total myocardial volume: $\mathrm{CT}_{\mathrm{m}} / \mathrm{CT}_{\mathrm{LV}}$.

Calculation of myocardial perfusion by EBCT-

The algorithm used for determining myocardial perfusion (in $\mathrm{ml} / 100 \mathrm{~g} / \mathrm{min}$ ) has been described previously by Rumberger et $a l,{ }^{17}$ and assumes a myocardial specific gravity of 1.05 $\mathrm{g} / \mathrm{ml}$ :

$$
\begin{aligned}
\left(\text { Area }_{\mathrm{m}} / \text { Area }_{\mathrm{LV}} \times \mathrm{t}_{\mathrm{m}}\right) \times 60 \mathrm{~s} / \mathrm{min} \\
\times \frac{100}{1.05 \mathrm{~g} / \mathrm{ml}}
\end{aligned}
$$

where Area $_{\mathrm{m}}$ and $\mathrm{Area}_{\mathrm{LV}}$ represent the areas under the indicator dilution curves from the myocardium and left ventricular cavity, respectively, and $t_{m}$ is the first pass mean transit time of the contrast through the myocardium, relative to the myocardial appearance time of contrast (identical to the "full width/half maximum time"). ${ }^{17}{ }^{23}$

This flow algorithm was used with the correction for intramyocardial vascular volume which incorporates $\beta$ (see Appendix for details of derivation):

$$
\begin{aligned}
& \left(\text { Area }_{\mathrm{m}} / \text { Area }_{\mathrm{LV}} \times \mathrm{t}_{\mathrm{m}}\right) \times 60 \mathrm{~s} / \mathrm{min} \times 100 \\
& \quad \times\left\{\frac{1}{1.05 \mathrm{~g} / \mathrm{ml}}+\frac{\beta}{1.05 \mathrm{~g} / \mathrm{ml} \times(1-\beta)}\right\}
\end{aligned}
$$

Measurements of $\beta$ and flow through each of the four tomographic slices were averaged for each scan to provide a single measurement of global flow as well as anterior, lateral, posterior, and septal regional flows. These were compared with the average flows for the corresponding regions determined by the microspheres.

HUMAN STUDIES

Fourteen healthy young male volunteers (mean age 31 years, range 18 to 43 years) without known cardiac disease were enrolled to study the feasibility of measuring myocardial perfusion with EBCT using intravenous contrast injections. All subjects were considered to be free from cardiac disease after review of their medical history, physical examination, resting 

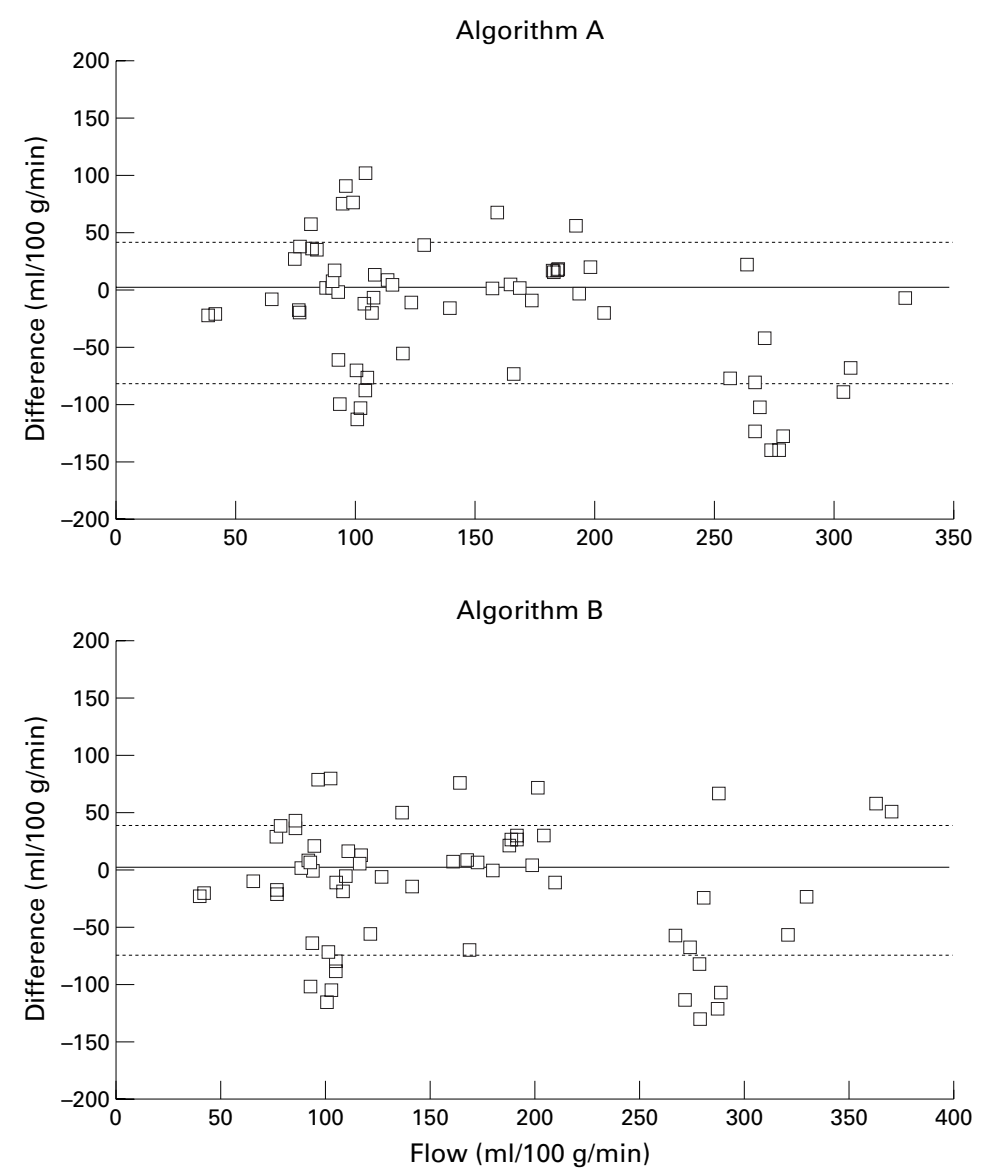

Figure 3 Bland and Altman plots showing comparison of regional myocardial perfusion measurements of EBCT, before $(A)$ and after $(B)$ correction for intramyocardial vascular volume, and radiolabelled microspheres obtained in the canine experiments. The abscissa is the mean of the EBCT and microsphere values and the ordinate is the difference between the two (EBCT minus microsphere). The dashed lines represent 1 standard deviation from the mean of the differences.

electrocardiogram, and serum cholesterol. No subject had a history of cigarette smoking and all were normotensive. Their mean weight was $83 \mathrm{~kg}$. All subjects gave written informed consent before the examination and the study was approved by the Mayo Clinic institutional review board.

\section{Volunteer preparation}

Subjects were studied in the fasting state. A $4.5 \mathrm{~F}$ angiographic catheter was placed percutaneously into a right brachial vein and advanced to the superior vena cava under fluoroscopic guidance. A peripheral intravenous line inserted in the left arm was available for infusion of adenosine (Medco Research Inc, Los Angeles, California, USA). Subjects were then placed supine within the gantry of the EBCT scanner. The electrocar-

Table 1 Linear regression equations and correlation coefficients ( $r$ ) for EBCT (y) measurements of regional myocardial perfusion compared to those measured simultaneously with radiolabelled microspheres $(x)$

\begin{tabular}{lccll}
\hline Region & $n$ & $\begin{array}{c}\text { Intercept } \\
(\mathrm{ml} / 100 \mathrm{~g} / \mathrm{min})\end{array}$ & Coefficient & $r(p$ Value) \\
\hline Lateral & 20 & 9.81 & 0.98 & $0.87(<0.001)$ \\
Anterior & 18 & 25.14 & 0.66 & $0.86(<0.001)$ \\
Septal & 10 & 29.29 & 0.72 & $0.81(<0.001)$ \\
Posterior & 15 & 28.08 & 0.63 & $0.82(<0.001)$ \\
\hline
\end{tabular}

diogram was monitored continuously and an automated blood pressure cuff was attached to the left arm.

Study protocol

The first three subjects had scans performed at rest to determine the optimal timing of contrast administration and optimal scanning position (cardiac axis). From these scans it appeared that the most uniform flow curves were obtained by imaging of transaxial slices. The subsequent 11 subjects had scans performed first at rest and then 10 minutes later during intravenous infusion of adenosine $(140 \mu \mathrm{g} / \mathrm{kg} /$ $\min )$.

\section{Scanning procedure}

Scans were performed using the same "flow mode" of the EBCT scanner as used for the animal studies while the subject suspended respiration for approximately 30 to 40 seconds. Twenty millilitres of iopamidol $(370 \mathrm{mg} \mathrm{I} / \mathrm{ml}$ ) at $10 \mathrm{ml} / \mathrm{s}$ were injected through the angiographic catheter immediately after the first of the 20 sequential images. Images were obtained at end systole (see below). When the perfusion imaging was complete, subjects were repositioned within the gantry by moving the table through a clockwise arc of $25^{\circ}$ and raising the patient's upper torso and head by approximately $25^{\circ}$. Such a position enabled imaging of true short axis ventricular slices for determination of left ventricular mass to exclude the presence of left ventricular hypertrophy. A 12 level (8 mm slices) volume scan, using single 50 $\mathrm{ms} /$ slice images acquired every second heart cycle at end diastole for approximately 10 to 15 seconds, was then performed during a $60 \mathrm{ml}$ injection of iopamidol at $3 \mathrm{ml} / \mathrm{s}$.

\section{Data analysis}

Myocardial perfusion was determined using algorithm B. Global and regional (anterior, lateral, and septal) flows were calculated from each of the four slices and then averaged to provide measurements of global and regional perfusion, respectively. Perfusion in these normal subjects was expected to be uniform throughout the heart and so homogeneity of measurements of flow and perfusion reserve was examined. Myocardial perfusion reserve ratio was calculated by dividing the flow measured during vasodilatation (during adenosine) by the corresponding global or regional flow at rest. Total left ventricular mass was determined using a previously validated method. ${ }^{26}$

\section{STATISTICS}

Mean and standard errors of the mean are used throughout to describe continuous data. Simple linear regression using the method of least squares was used to determine correlation between EBCT and microsphere data and agreement between the two datasets was illustrated using Bland and Altman plots. ${ }^{27}$ Student's $t$ test (paired and unpaired where appropriate) was used for comparison of continuous data in the human studies. A level of statistical significance was assumed as $\mathrm{p}<0.05$. 
Table 2 Haemodynamic data recorded in human subjects at rest and with intravenous adenosine

\begin{tabular}{|c|c|c|c|c|c|c|c|}
\hline \multirow[b]{2}{*}{ Haemodynamic variable } & \multicolumn{2}{|c|}{ Rest $(n=14)$} & \multicolumn{2}{|c|}{ Rest $(n=10)$} & \multicolumn{3}{|c|}{ Adenosine $(n=10)$} \\
\hline & Precontrast & Post-contrast & Precontrast & Post-contrast & Preinfusion & Peak infusion & Post-contrast \\
\hline Heart rate (beats/min) & $62(10)$ & $61(10)$ & $57(4)$ & $57(5)$ & $58(6)$ & $79(17)^{\star}$ & $77(15)^{\star}$ \\
\hline $\begin{array}{l}\text { Mean arterial pressure } \\
(\mathrm{mm} \mathrm{Hg})\end{array}$ & $77(9)$ & $78(8)$ & 77 (10) & $79(7)$ & $78(10)$ & $78(8)$ & $76(10)$ \\
\hline
\end{tabular}

${ }^{\star} \mathrm{p}<0.01 v$ preinfusion value.

Values are mean (SEM).

\section{Results}

ANIMAL STUDIES

Twenty five EBCT scans were performed with simultaneous microsphere injections. Technical problems with microsphere administration and improper timing of the contrast injection during some scans resulted in the loss of four pairs of microsphere and EBCT data. There were potentially 21 EBCT scans with 21 measurements of global perfusion and 84 regional measurements $(21 \times$ four quadrants $)$. Image misregistration and reconstruction imaging artefacts resulted in uninterpretable scans accounting for the absence of seven measurements of global flow and 21 regional measurements. Data are therefore presented from 14 global and 63 regional flow measurements.

Myocardial perfusion

Global-The estimated global intramyocardial vascular volume ranged from $2.8 \%$ at rest to $17.0 \%$ during graded infusions of adenosine. These measurements correlated closely to flow rates by microspheres of 57 to $346 \mathrm{ml} / 100$ $\mathrm{g} / \mathrm{min}(r=0.94$; fig 1$)$. Comparison between the two measurements of perfusion is shown graphically with and without correction for intramyocardial vascular volume (fig 2 ). The agreement between the two measurements is modest but improved with algorithm B (fig 2B). The correlation between flow algorithm (A) and microsphere data was: $\mathrm{y}=0.59 \mathrm{x}+$ $15.6(r=0.86)$. Use of algorithm $\mathrm{B}$, which accounted for intramyocardial vascular volume, improved the prediction of microsphere flow: $\mathrm{y}=0.72 \mathrm{x}+6.06 \quad(r=0.88)$. The regression models for the two algorithms were compared statistically by examining the correlation between the differences (A minus B) and the microsphere measurements. This correlation proved to be significant $(r=0.90$, $\mathrm{p}<0.0001$ ), indicating that the regression analysis for model B was statistically different from model A.

Regional-Bland and Altman analyses of the agreement between the two measurements of regional perfusion are shown in fig 3 . The wide differences in agreement between the two

Table 3 Comparison of EBCT derived measurements of myocardial perfusion at rest and during adenosine infusions; perfusion reserve is also shown

\begin{tabular}{lrlrl}
\hline Region & $\begin{array}{l}\text { Rest } \\
(n=10)\end{array}$ & $\begin{array}{l}\text { Adenosine } \\
(n=10)\end{array}$ & \multicolumn{1}{c}{ p Value } & $\begin{array}{l}\text { Perfusion reserve } \\
(n=10)\end{array}$ \\
\hline Global & $93(5)$ & $250(19)$ & $<0.0001$ & $2.8(0.2)$ \\
Anterior & $107(9)$ & $255(19)$ & 0.0003 & $2.5(0.3)^{\star}$ \\
Lateral & $104(7)$ & $281(28)$ & $<0.0001$ & $2.8(0.3)$ \\
Septum & $96(5)$ & $267(20)$ & $<0.0001$ & $3.0(0.3)^{\star}$ \\
\hline
\end{tabular}

Values are mean (SEM), $\mathrm{ml} / 100 \mathrm{~g} / \mathrm{min}$

${ }^{\star}$ Missing data for one rest scan (see text for details).

EBCT, electron beam computed tomography. measurements with no correction for intramyocardial vascular volume seen in fig $3 \mathrm{~A}$ are much less evident when the correction was used (fig 3B). The correlation between regional EBCT measurements and microspheres using algorithm A was $r=0.74$ with a regression slope of 0.55 . The correlation using algorithm B was $r=0.82$ with a regression slope of 0.75 . Correlations for each of the four different myocardial quadrants using algorithm $\mathrm{B}$ are shown in table 1: the closest association between EBCT and microsphere data was found in the lateral wall (regression slope $=0.98, r=0.87$ ) while the association was poorest in the posterior wall (regression slope $=0.63, r=0.82)$.

HUMAN STUDIES

Although the measurement of myocardial perfusion was reasonably accurate in the animal studies, several problems were evident. Imaging artefacts were a problem in some scans and probably accounted for much of the variation seen in figs 2 and 3. As some of the imaging artefacts probably represented noise in the data, it was hypothesised first, that larger myocardial slices in human subjects relative to those in dogs - particularly if imaged at end systole rather than end diastole-would improve the signal to noise ratio, as would imaging in the neutral rather than the short axis; and second, that limiting the amount of contrast to $20 \mathrm{ml}$ would potentially minimise image artefacts in the adjacent myocardium as the contrast passed through the left ventricle.

All 14 subjects were studied at rest but two curves were uninterpretable in the anterior region in one subject and the interventricular septum in another. In one of the 11 subjects who received adenosine, no image data were acquired because of a technical problem with the scanner. Thus data regarding myocardial perfusion reserve were available for 10 subjects. No significant complications occurred during any of the scans, although flushing or mild chest discomfort occurred in some subjects associated with the adenosine infusion, resolving spontaneously without the need for dose reduction. Transient and asymptomatic second degree heart block occurred in one subject during the adenosine infusion but did not require any action. No significant changes in heart rate or blood pressure were documented during contrast injections (table 2). Data are shown for all patients at rest and separately for the 10 patients who received adenosine. During adenosine infusion, a small but significant increase in heart rate was observed from (mean (SEM)) 58 (6) to 79 (17) beats/min, and to 77 (15) beats/min immediately after cessation of the infusion $(\mathrm{p}<0.01$ for trend), 

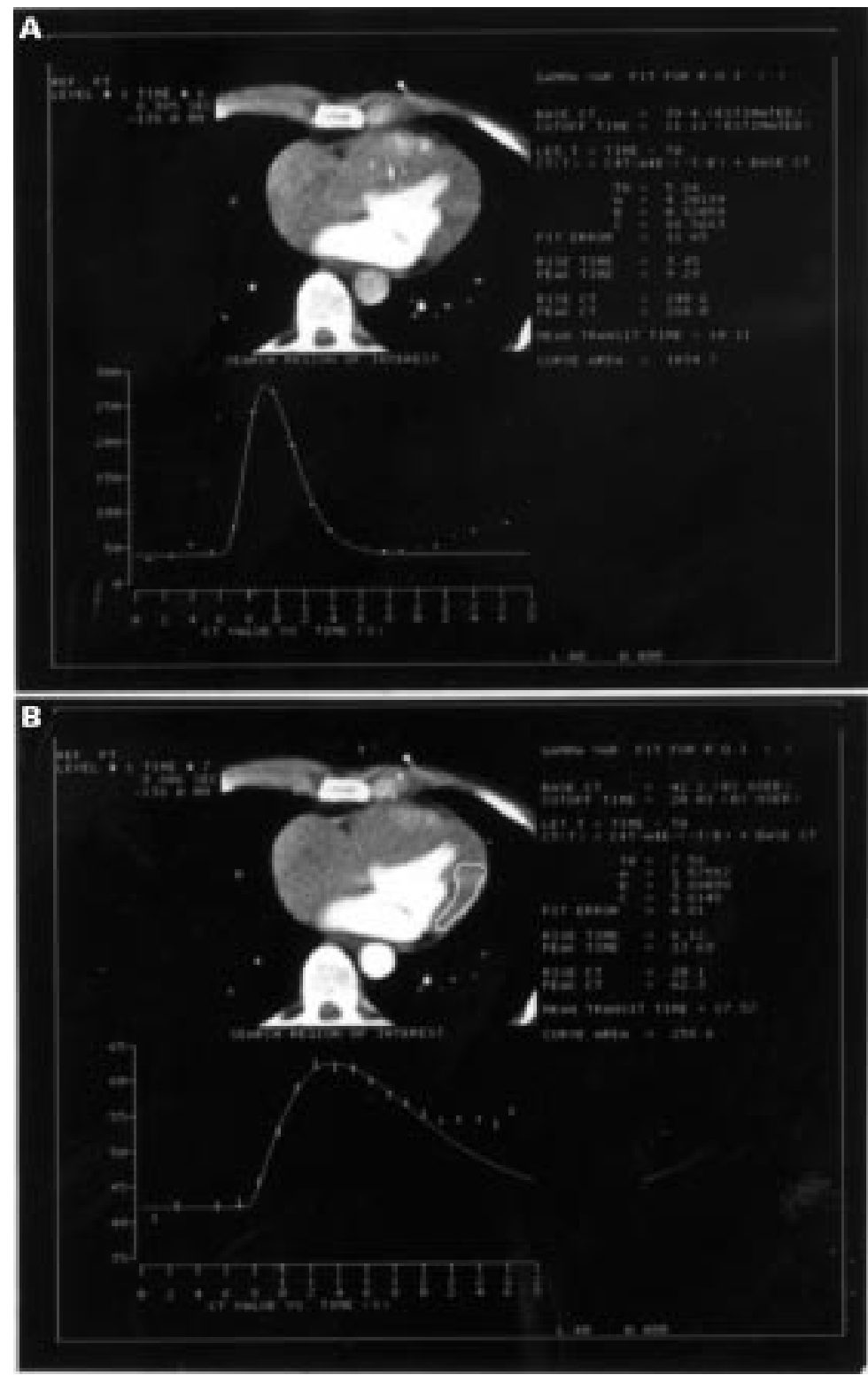

Figure 4 Example of contrast clearance curves obtained from the left ventricular cavity $(A)$ and the lateral ventricular wall $(B)$ in one volunteer during infusion of adenosine. Contrast (white) is seen within the left ventricular cavity and the region of interest over the lateral wall is defined by the white tracing. The change in CT number on the ordinate is shown as a function of time on the abscissa. but no significant change in mean arterial pressure was noted

The mean (SEM) resting global myocardial flow measured with EBCT in the 14 subjects was 98 (6) $\mathrm{ml} / 100 \mathrm{~g} / \mathrm{min}$. Average regional flow in the anterior wall was $109(9) \mathrm{ml} / 100 \mathrm{~g} / \mathrm{min}$, in the lateral wall $111(8) \mathrm{ml} / 100 \mathrm{~g} / \mathrm{min}$, and in the septal wall 102 (6) $\mathrm{ml} / 100 \mathrm{~g} / \mathrm{min}$ (NS). In the 10 subjects who had perfusion reserve assessed (table 3), global flow at rest was 93 (5) and increased to 250 (19) during adenosine $(\mathrm{p}<0.001)$ with an average perfusion reserve of 2.8 (0.2). Similar and uniform changes in myocardial perfusion and perfusion reserve were observed in the anterior, lateral, and septal regions. Average regional perfusion reserve among all subjects was $2.8(0.3)$ (range 1.1 to 4.9). Compared with the animal studies, there were far fewer imaging artefacts seen in the human studies. An example of left ventricular and myocardial contrast clearance curves from one subject is shown in fig 4 .

Left ventricular mass measurements were available in 13 of the 14 subjects and averaged 148 (5) $\mathrm{g}\left(73(2) \mathrm{g} / \mathrm{m}^{2}\right)$ which is within the range for normal subjects. ${ }^{28}$

\section{Discussion}

This study shows that EBCT can be used to quantify global and regional myocardial perfusion accurately when an estimate of intramyocardial vascular volume is included in the measurement. The major limitation of this technique potentially lies with imaging artefacts, which accounted for uninterpretable contrast clearance curves in approximately $25-30 \%$ of all measurements in the animal studies but was less common in the human studies. Global and regional myocardial perfusion and perfusion reserve measurements were consistent with those expected in normal subjects.

Although EBCT has been found to be applicable to the measurement of myocardial perfusion in previous animal studies, high flow rates have been significantly underestimated. ${ }^{1617}$ Other investigators, using intraaortic contrast injections, ${ }^{18}{ }^{29}$ have shown that this problem can be overcome if dynamic changes in intramyocardial vascular volume during coronary vasodilatation are taken into account. We derived a parameter for estimating intramyocardial vascular volume with EBCT which was consistent with historical measurements using different measurement techniques. ${ }^{203031}$ Total myocardial vascular volume is approximately $7 \%$ and can increase to approximately $15-18 \%$ when perfusion pressure is increased ${ }^{20}$ or if adenosine is given. ${ }^{31}$ EBCT estimates of intramyocardial vascular volume ranged from $2.8 \%$ at rest to $17.0 \%$ during coronary vasodilatation in our study. Incorporation of this variable in the flow algorithm resulted in better agreement between EBCT measurements of myocardial perfusion and microspheres (algorithm B), reflected by the differences in the Bland-Altman analyses in figs 2 and 3. The lateral wall measurements were particularly encouraging, with a correlation coefficient of 0.87 and regression slope of 0.98. Our data support the hypothesis that accounting for intramyocardial vascular volume is necessary for the accurate prediction of myocardial perfusion by EBCT using intravenous injections.

Encouraged by the animal data, we studied measurement of perfusion in human volunteers with EBCT and intravenous contrast injections. The studies were performed without significant complications and generally required 30 minutes or less; the actual scanning duration was less than one minute. Breath holding is a requirement for optimal imaging and many sick or elderly patients would not be able to do this for the 30-40 seconds required in this study. However, future developments with EBCT may obviate the need for prolonged breath holding. Imaging of the human 
heart resulted in very smooth contrast clearance curves (fig 4). Almost all scans were interpretable in human studies, in contrast with the animal experiments. As would be expected in normal subjects, measurements of perfusion were found to be relatively homogeneous across all regions of the heart.

There are significant limitations to the currently available techniques for the measurement of myocardial perfusion and coronary flow reserve in human subjects ${ }^{12} 32$ and none was considered an ideal reference standard for use in this study. However, perfusion measurements at rest and after intravenous adenosine were similar to those reported from experiments in normal volunteers using positron emission tomographic imaging. ${ }^{13-15}$ Myocardial perfusion measurements using ${ }^{13} \mathrm{~N}$ labelled ammonia and ${ }^{15} \mathrm{O}$ labelled water imaging have been reported to be 70 to $90 \mathrm{ml} / 100 \mathrm{~g} / \mathrm{min}$ at rest, ${ }^{13-15}$ increasing to $135 \mathrm{ml} / 100 \mathrm{~g} / \mathrm{min}$ with exercise $^{13}$ and to 230 to $355 \mathrm{ml} / 100 \mathrm{~g} / \mathrm{min}$ after dipyridamole. ${ }^{14}{ }^{15}$ Flow reserve in the study of Di Carli et al among normal subjects was 2.6 (0.7) (mean (SD)), ${ }^{15}$ compared with 2.5 to 3.0 obtained in the current study. These are also consistent with those observed in normal subjects using Doppler velocity measurements after papaverine induced coronary vasodilatation $(2.9$ to 3.2$){ }^{11}$

Ludman et al have also reported EBCT measurement of myocardial perfusion in people ${ }^{33}$ but regional perfusion in normal subjects in that study was substantially lower both at rest and during coronary vasodilatation than in the current study. Corresponding regional perfusion reserve ratios ranged from 0.4 to 2.2 (mean 1.62) compared to a range of 1.1 to 4.9 (mean 2.8) in the present study. The observations of Ludman and colleagues ${ }^{33}$ are consistent with previous animal studies in which high flow rates were underestimated with no correction for intramyocardial vascular volume. ${ }^{16} 1719$

Much of the discordance between EBCT and microsphere measurements of flow in our animal studies may have been the result of imaging artefacts. A full description of these is beyond the scope of this paper but image reconstruction artefacts are generally related to beam hardening or photon (Compton) scatter. These effects occur as the energy spectrum of $x$ rays passing through the vertebral column and through the iodine filled, adjacent left ventricular cavity become "distorted" in myocardial regions. Such imaging artefacts are significantly reduced when intra-aortic contrast injections are employed, ${ }^{18}{ }^{29}$ although this approach requires invasive arterial catheterisation.

Comparison with microspheres in the animal studies may have resulted in errors from temporal heterogeneity in flow, since these measurements were averaged over a few minutes rather than the 20 to 30 seconds required to perform the EBCT scan. Heterogeneity in regional or spatial flow exists in many animal hearts, often with significant variability, ${ }^{34-37}$ and may have important implications for our data since the matching of the necropsy specimens to the in vivo images may not have been exact.

An important assumption in applying indicator dilution theory is that the contrast agent remains entirely intravascular during its first pass. $^{2425}$ Canty et al have challenged this assumption and shown that the extraction of conventional iodinated contrast agents is not negligible and actually varies with flow. ${ }^{38}$ For practical purposes this probably does not affect algorithms that include the peak rise in CT number but it may affect algorithms incorporating estimates of area under the contrast clearance curve.

The full potential value of EBCT for the minimally invasive assessment of coronary artery disease remains to be defined. EBCT can accurately identify coronary atherosclerotic plaque ${ }^{39-41}$ and its further application to the determination of the physiological significance of such findings by measuring myocardial perfusion may make it a convenient method for the diagnosis of the severity of coronary artery disease during a single imaging session. Research into evaluating imaging artefacts continues, and minimising these artefacts with new reconstruction algorithms will be a necessary requirement before EBCT can be widely used in clinical trials.

Adenoscan was generously supplied by Medco Research Inc, Los Angeles, California, USA. We thank Richard E Wiener for his invaluable technical help during these studies and Patrick F Sheedy MD for providing technical assistance with the EBCT Sheedy MD for providing technical assistance with the EBCT
scans. This study was supported by Grant HL 34508, National Institutes of Health, Bethesda, Maryland, The Whitaker Foundation, Mechanicsburg, Pennsylvania, and the Mayo Clinic and Foundation.

\section{Appendix}

Radiolabelled microsphere measurements of myocardial perfusion are expressed in terms of flow per unit mass $(\mathrm{ml} / \mathrm{g} / \mathrm{min}$ ) based on the mass of the postmortem myocardium. EBCT measurements, on the other hand, are first defined as flow per unit volume $(\mathrm{ml} / \mathrm{ml} / \mathrm{min})$. To convert the EBCT derived flow to flow per unit mass requires the proper factor relating in vivo tissue volume to ex vivo muscle mass. If it is assumed that the total myocardial tissue volume (V) is composed of two compartmental volumes of muscle $\left(\mathrm{V}_{\mathrm{M}}\right)$ and blood filled vasculature $\left(\mathrm{V}_{\mathrm{B}}\right)$ then,

$$
\mathrm{V}=\mathrm{V}_{\mathrm{M}}+\mathrm{V}_{\mathrm{B}}
$$

It is known that the volume of $V_{M}$ is equivalent to the mass of muscle $(\mathrm{M})$ divided by its specific gravity ( $p=$ $1.05 \mathrm{~g} / \mathrm{ml}$ ) and so,

$$
\mathrm{V}=\mathrm{M} / p+\mathrm{V}_{\mathrm{B}}
$$

Therefore, by substitution of equation 2, flow per unit volume can be expressed as,

$$
\mathrm{F} / \mathrm{V}=\mathrm{F} /\left(\mathrm{M} / \mathrm{p}+\mathrm{V}_{\mathrm{B}}\right)
$$

and flow per unit mass can then be derived as, $\mathrm{F} / \mathrm{M}=(\mathrm{F} / \mathrm{V}) \times\left(1 / p+\mathrm{V}_{\mathrm{B}} / \mathrm{M}\right)$

The only unknown in equation 4 is " $\mathrm{V}_{\mathrm{B}} / \mathrm{M}$ " (that is, the ratio of vascular volume to muscle mass). In the Methods section, the partial volume parameter of intramyocardial vascular volume $(\beta)$ represented the percent of the total myocardial tissue volume composed of blood filled vasculature, defined as: $\beta=V_{\mathrm{B}} / \mathrm{V}$

Substituting equation (2) for $\mathrm{V}$ yields,

and therefore,

$$
\beta=\mathrm{V}_{\mathrm{B}} /\left(\mathrm{M} / p+\mathrm{V}_{\mathrm{B}}\right)
$$

$$
\mathrm{V}_{\mathrm{B}} / \mathrm{M}=\beta /(p-p \beta)
$$

Substitution with equation 6 for the term "V $/ M$ " in equation (4) results in the proper relation of EBCT flow per unit volume to EBCT flow per unit mass (algorithm $\mathrm{B}$ in methods):

$$
(\mathrm{F} / \mathrm{M})_{\mathrm{CT}}=(\mathrm{F} / \mathrm{V})_{\mathrm{CT}} \times\{1 / p+\beta /(p-p \beta)\}(7)
$$


The theoretical range of values for $\beta$ is from zero to one and is estimated from the EBCT data as discussed in detail in the text.

1 DeRouen TA, Murray JA, Owen W. Variability in the analy-

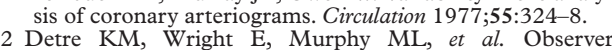
agreement in evaluating coronary angiograms. Circulation agreement in evalus

3 Grondin CM, Dyrda I, Pasternac A, et al. Discrepancies between cineangiographic and postmortem findings in patients with coronary artery disease and recent myocardial revascularization. Circulation 1981;49:703-8.

4 Isner JM, Kishel J, Kent KM, et al. Accuracy of angiographic determination of left main coronary arterial narrowing. Circulation 1981;63:1056-64.

5 Vlodaver Z, Frech R, Van Tassel RA, et al. Correlation of the antemortem coronary arteriogram and the postmortem specimen. Circulation 1973;47:162-9.

6 Zir LM, Miller SW, Dinsmore RE, et al. Interobserver variability in coronary angiography. Circulation 1976;53:627-

32 .
7 Wilson RF, Laughlin DE, Ackell PH, et al. Transluminal subselective measurement of coronary artery blood flow velocity and vasodilator reserve in man. Circulation 1985;72:82-92.

8 Wilson RF, Marcus ML, White CW. Prediction of the physiologic significance of coronary arterial lesions by physiologic significance of coronary arterial lesions by quantitative lesion geometry in patients with limit
ary artery disease. Circulation 1987;75:723-32.

9 White CW, Wright CB, Doty DB, et al. Does visual interpretation of the coronary arteriogram predict the physiologic importance of a coronary stenosis? $N$ Engl $f$ Med 1984;310:819-24.

10 Harrison DG, White CW, Hiratzka LF, et al. The value of lesion cross-sectional area determined by quantitative coronary angiography in assessing the physiologic significance of proximal left anterior descending coronary arterial stenoses. Circulation 1984;69:1111-19.

11 Kern MJ, Tatineni S, Gudipati C, et al. Regional coronary blood flow velocity and vasodilator reserve in patients with angiographically normal coronary arteries. Coronary Art Dis 1990;1:579-89.

12 Marcus ML, Wilson RF, White CW. Methods of measurement of myocardial blood flow in patients: a critical review. Circulation 1987;76:245-53.

13 Krivokapich J, Smith GT, Huang S-C, et al. ${ }^{13} \mathrm{~N}$ Ammonia myocardial imaging at rest and with exercise in normal volunteers. Quantification of absolute myocardial perfusion with dynamic positron emission tomography. Circulation 1989;80:1328-37.

14 Bergmann SR, Herrero P, Markham J, et al. Noninvasive quantitation of myocardial blood flow in human subjects with oxygen-15-labeled water and positron emission tomography. F Am Coll Cardiol 1989;14:639-52.

15 Di Carli M, Czernin J, Hoh CK, et al. Relation among stenosis severity, myocardial blood flow, and flow reserve in patients with coronary artery disease. Circulation 1995;91: 1944-51.

16 Gould RG, Lipton MJ, McNamara MT, et al. Measurement of regional myocardial blood flow in dogs by ultrafast CT. Invest Radiol 1987;23:348-53.

17 Rumberger JA, Feiring AJ, Lipton MJ, et al. Use of ultrafast computed tomography to quantitate regional myocardial perfusion: a

18 Wang T, Wu X, Chung N, et al. Myocardial blood flow estimated by synchronous, multislice, high-speed computed tomography. IEEE Trans Med Imaging 1989;8:70-7.

19 Wolfkiel CJ, Ferguson JL, Chomka EV, et al. Measurement of myocardial blood flow by ultrafast computed tomography. Circulation 1987;76:1262-73.

20 Morgenstern C, Höljes U, Arnold G, et al. The influence of coronary pressure and coronary flow on intracoronary blood volume and geometry of the left ventricle. Pflügers Arch 1973;340:101-11.
21 Boyd DB. Computerized transmission tomography of the heart using scanning electron beams. In: Higgins $\mathrm{CH}$, ed. Computed tomography of the heart and great vessels. Mount Kisco, New York: Futura Publishing Company, 1983:4555

22 Rumberger JA, Stanford W, Marcus ML. Quantitation of regional myocardial perfusion by ultrafast-CT. Am $\mathcal{F}$ Card Imaging 1987;1:336-43.

23 Rumberger JA, Bell MR, Feiring AJ, et al. Measurement of myocardial perfusion using fast computed tomography. In: Marcus ML, Schelbert HR, Skorton DJ, Wolf GL, eds. Cardiac imaging. A companion to Braunwald's heart disease. Philadelphia: WB Saunders Company, 1991:688-702.

24 Newhouse JH. Fluid compartment distribution of intravenous iothalamate in the dog. Invest Radiol 1977;12:3647.

25 Newhouse JH, Murphy RX. Tissue distribution of soluble contrast: effect of dose variation and changes with time. $\mathrm{Am}$ f Roentgenol 1981;136:463-7.

26 Feiring AJ, Rumberger JA, Skorton SM, et al. Determination of left ventricular mass in the dog with rapid acquisition cardiac CT scanning. Circulation 1985;72: $1355-64$

27 Bland JM, Altman DG. Statistical methods for assessing agreement between two methods of clinical assessment. Lancet 1986;i:307-10

28 Feiring AJ, Rumberger JA. Ultrafast computed tomography analysis of regional radius-to-wall thickness ratios in normal and volume overloaded human left ventricle. Circulation 1992;85:1423-32.

29 Weiss RM, Otoadese EA, Noel MP, et al. Quantitation of absolute regional perfusion using cine computed tomography. $\mathcal{F}$ Am Coll Cardiol 1994;23:1186-93.

30 Crystal GJ, Downey HF, Bashour FA. Small vessel and total coronary blood volume during intracoronary adenosine. Am f Physiol 1981;241:H194-201.

31 Weiss HR, Winbury ML. Nitroglycerin and chromonar on small-vessel blood content of the ventricular walls. $A m \mathcal{F}$ Physiol 1974;226:838-42.

32 Ritman EL. Angiographic measurement of coronary blood flow reserve. Does it work? I Am Coll Cardiol 1990;82 1533-5.

33 Ludman PF, Coats AJS, Burger P, et al. Validation of measurement of regional myocardial perfusion in humans by ultrafast $x$ ray computed tomography. Am f Card Imaging 1993; 7:267-79.

34 Franzen D, Conway RS, Zhang $\mathrm{H}$, et al. Spatial heterogeneity of local blood flow and metabolite content in dog hearts. Am F Physiol 1988;254:H344-53.

35 Austin RE, Aldea GS, Coggins DL, et al. Profound spatial heterogeneity of coronary flow reserve. Discordance between patterns of resting and maximal myocardial blood flow. Circ Res 1990;67:319-31.

36 King RB, Bassingthwaighte JB, Hales JRS, et al. Stability of heterogeneity of myocardial blood flow in normal awake baboons. Circ Res 1985;57:285-95.

37 Marcus ML, Kerber RE, Ehrhardt JC, et al. Spatial and temporal heterogeneity of left ventricular perfusion in awake dogs. Am Heart 7 1977; 94:748-54.

38 Canty JM, Judd RM, Brody AS, et al. First-pass entry of nonionic contrast into the myocardial extravascular space. Effects on radiographic estimates of transit time and blood volume. Circulation 1991;84:2071-8.

39 Tanenbaum SR, Kondos GT, Veselik KE, et al. Detection of calcific deposits in coronary arteries by ultrafast computed tomography and correlation with angiography. Am $\mathcal{7}$ Cardiol 1989;63:870-2.

40 Agatston AS, Janowitz WR, Hildner FJ, et al. Quantification of coronary artery calcium using ultrafast computed tomography. $f$ Am Coll Cardiol 1990;15:827-32.

41 Rumberger JA, Sheedy PF, Breen JF, et al. Coronary calcium, as detected by electron beam computed tomography, and coronary disease on arteriogram. Effect patient's sex on diagnosis. Circulation 1995;91:1363-7. 